\title{
Testing the accuracy of high-resolution satellite-based and numerical model output precipitation products over Ethiopia
}

\author{
Getachew Dubache ${ }^{1} \cdot$ Birhanu Asmerom ${ }^{2} \cdot$ Waheed Ullah $^{1} \cdot$ Bob Alex Ogwang ${ }^{3} \cdot$ Farshad Amiraslani $^{4} \cdot$ Zhu Weijun $^{5}$. \\ Chaman Gul ${ }^{1}$
}

Received: 18 November 2020 / Accepted: 15 September 2021 / Published online: 27 September 2021

(c) The Author(s) 2021

\begin{abstract}
The indirect rainfall estimates by satellites and numerical models are the alternative options for the regions lacking enough and accurate ground observations. However, these indirect estimates often lack homogeneity and need to be evaluated before application. This study used gauge observations to test the accuracy of recently produced high-resolution satellite-based and numerical model output rainfall products over Ethiopia. Tropical Applications of Meteorology Using Satellite data and GroundBased Observations (TAMSAT v3.1), Climate Hazard group Infrared Precipitation with Stations (CHIRPS v2.0), and the ERA5 reanalysis products were evaluated at monthly, seasonal, and annual temporal scales for the years 1992-2009. The satellite products showed nearly similar characteristics with much better accuracy than the model reanalysis output, which underestimated the rainfall amounts. Both satellite and reanalysis products captured the shapes of the rainfall at a monthly scale but less accurately at a seasonal scale. In general, the satellite-based products outperformed the reanalysis data set with a high correlation coefficient and index of agreement values, as well as low Root Mean Square Error and BIAS values. On the other hand, the reanalysis (ERA5) product showed a considerable underestimation in all sites. Therefore, satellite-based products are more reliable for researches in the region. However, the algorithms in both satellites need further calibration for a better estimation of seasonal rainfall amounts.
\end{abstract}

\section{Introduction}

Due to global climate change, accurate rainfall forecasts in association with agricultural activities are needed more than ever, especially in Africa, in which the continent's economy badly depends on rain-fed agriculture. Eastern Africa, including Ethiopia, is exceedingly vulnerable to climate

Getachew Dubache

g.dubache@ reading.ac.uk

1 College of Reading Academy, Nanjing University of Information Science and Technology, Nanjing 210044, China

2 School of Atmospheric Physics, Nanjing University of Information Science and Technology, Nanjing 210044, China

3 Uganda National Meteorological Authority, P. O. Box 7025, Kampala, Uganda

4 Faculty of Life and Health Sciences, School of Geography and Environmental Sciences, Ulster University, Coleraine BT52 1SA, UK

5 School of Marine Science, Nanjing University of Information Science and Technology, Nanjing 210044, China change and needs accurate rainfall measurements to monitor agricultural resources. Unfortunately, the ground-based observations in Africa are insufficient due to the spatial and temporal discontinuities (Schreck and Semazzi 2004). Due to reduced rainfall, Ethiopia had been frequently exposed to famine from drought, which mainly occurred due to a lack of proper (skilled) forecast based on ground observations. For the past few decades, Scientists have been producing the indirect rainfall estimates from the satellite imagery and Numerical Weather Prediction model outputs at different spatial and temporal resolutions (e.g., Becker et al. 2013; Bergès et al. 2010; Harris et al. 2014; Herman et al. 1997; Huffman et al. 2010; Menne et al. 2012; Novella et al. 2013; Roebeling et al. 2012; Schneider et al. 2014). Most African countries have benefited from the freely available satellitebased and numerical model reanalysis output products. Nowadays, there are several freely available satellite-based and numerical model output alternatives, but these indirectly estimated products need to be validated before application. One of the most common questions among scientific community platforms is "which rainfall data set is appropriate for this and that research sector?" Such questions need to be addressed carefully as the rainfall is very sensitive to various 
conditions (e.g., topography), despite that many still conduct researches based on suggestions provided without verification. The availability of these data sets by itself is not enough until it gets validated and verified.

Compared to the production rate of the satellite-based and model output products, little validation works have been conducted in various regions. The Climate Hazard group Infrared Precipitation with Stations (CHIRPS v2.0) is one of the popular products to be validated in multiple countries, e.g., China (Bai et al. 2018), Pakistan (Ullah et al. 2019), and Africa (Nkunzimana et al. 2020a; Ayehu et al. 2018; Dinku et al. 2018). Some of the satellite-based products, including CHIRPS and the Tropical Applications of Meteorology Using Satellite Data and Ground-Based Observations (TAMSAT Versions 2 and 3), were validated in different regions of East Africa (e.g., Dinku et al. 2011, 2007, 2008a, 2008b; Koutsouris et al. 2016; Nkunzimana et al. 2020b; Romilly et al. 2011). On the other hand, the reanalysis model output products were also validated in Africa. For example, Maidment et al. (2013) validated ERA-Interim and ERA40 products in Uganda, while Zhang et al. (2013) validated eight different reanalysis products in South Africa.

The latest validation work, which has an association with this study, was conducted in east Africa. Dinku et al. (2018) evaluated
The Climate Hazards Group Infrared Precipitation (CHIRP) and CHIRPS products over East Africa (Ethiopia, Kenya, Somalia, Uganda, Rwanda, and Tanzania) at daily, dekadal (10-day), and monthly time scales. They compared these products with TAMSAT $(2,3)$ and the African Rainfall Climatology version 2 (ARC2). The same products were evaluated at nearly the same time by Ayehu et al. (2018), but this time limited to only the upper Blue Nile river basin region of Ethiopia. Some other satellite-based and reanalysis products were also validated in Uganda (Maidment et al. 2013), Burundi (Nkunzimana et al. 2020a), and Tanzania (Koutsouris et al. 2016).

This paper is intended to validate three products against the independent gauge observations at monthly, seasonal, in fact, the primary rainy season (June-September), and annual time scale in six selected regions of Ethiopia (Fig. 1b). The first product is CHIRPS, chosen because of its high resolution and performance in the region at daily, dekadal, and monthly time scales (Ayehu et al. 2018; Dinku et al. 2018). Secondly, the latest release (version 3.1) of Tropical Applications of Meteorology Using Satellite Data and Ground-Based Observations (TAMSAT). This product has the best resolution in Africa and is designed to provide accurate rainfall estimates to the continent. It has better performance than CHIRPS daily and is nearly similar at dekadal time
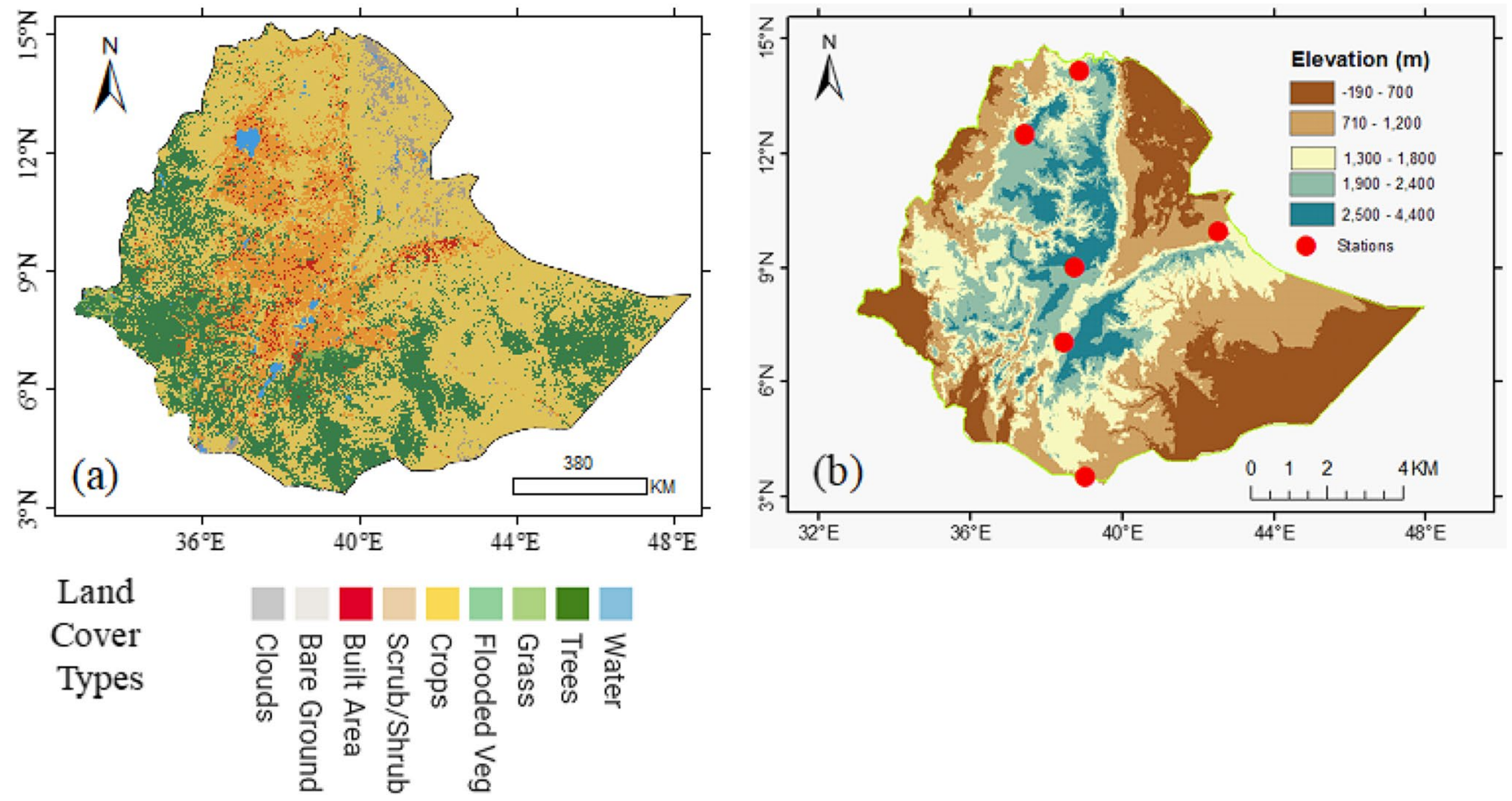

Fig. 1 Map of the study area (a) land cover (b) topography with specific study sites. In figure 1 above the subfigure (a) is a land cover map of the study area with a ten-class global land use/land cover (LULC) map for 2020 at 10-meter resolution. The map is derived from ESA Sentinel-2 imagery at $10 \mathrm{~m}$ resolution. This map was produced by a deep learning model trained using over 5 billion hand-

labeled Sentinel-2 pixels, sampled from over 20,000 sites distributed across all major biomes of the world (Esri 2021). Since Snow/Ice is not common in this region, only nine land cover types were considered from the ESRI land cover products. Subfigure (b) is for the topography map of the study area, with the locations of specific analysis sites 
scales (Dinku et al. 2018). The latest TAMSAT (version 3.1), which has not been validated in the region, is considered in this study. The third product considered for further validation in this paper is the fifth-generation reanalysis (ERA5) by the European Center for Medium-Range Weather Forecasts (ECMWF). The previous versions of this product, such as ERA-Interim and ERA-40, which are freely available at $0.75^{\circ}$ spatial resolution, have been widely applied in various research sectors across the world. Despite its popularity, many still argue its appropriateness in Africa due to the less accuracy of modeled rainfall estimates than satellite-based products (Diro et al. 2009; Lim and Ho 2000; Maidment et al. 2013; Poccard et al. 2000). The previous versions, ERAInterim and ERA-40, were evaluated in Uganda (Maidment et al. 2013). The latest version (ERA5) is selected for validation in this study because of the following reasons: (a) Due to the finest resolution $\left(0.25^{\circ}\right)$ compared to the previous versions $\left(0.75^{\circ}\right)$, (b) To test if the current version is improved and reliable in the region compared to the previous reports by (Maidment et al. 2013), and (c) Compare with the above two satellite-based products and see if this product could reverse the doubt (Diro et al. 2009; Lim and Ho 2000; Maidment et al. 2013; Poccard et al. 2000). So, validating this product would help to understand if it is reliable or not as well as its performance compared to satellite-based products.

\section{Study regions}

The study region (Ethiopia) belongs to the sub-tropics $\left(3.30^{\circ}-15^{\circ} \mathrm{N}, 33^{\circ}-48^{\circ} \mathrm{E}\right)$ and experiences tri-modal rainfall regime: October-January, February-May, and the main rainy season (June-September) that accounts for $50-80 \%$ of annual rainfall (Dubache et al. 2019a, 2019b). Therefore, most of the agricultural productivity depends on rain during June-September season. Among the six selected study sites in this study, at least four falls in this major rain season (Fig. 1b). The sites were chosen carefully, considering the region's complex topography (Fig. 1b) and the variety of land cover types (Fig. 1a). Additional information on the locations of selected study sites is included in Table 1.

Table 1 Locations and their elevations of the selected study sites

\begin{tabular}{lcll}
\hline Station & Latitude $\left(^{\circ}\right)$ & Longitude $\left(^{\circ}\right)$ & Elevation $(\mathrm{m})$ \\
\hline Bole & 9.03 & 38.75 & 2354 \\
Dire & 9.97 & 42.53 & 1180 \\
Awassa & 7.06 & 38.48 & 1694 \\
Gondar & 12.52 & 37.43 & 1973 \\
Moyale & 3.55 & 39.03 & 1166 \\
Adwa & 14.18 & 38.88 & 1911 \\
\hline
\end{tabular}

The full name for "Dire" and 'Bole"' in Tables 1, 2, 3, and 4 stands for the Dire Dawa and Bole Addis Ababa gauge stations or study sites
In Fig. 1 above the subfigure (a) is a land cover map of the study area with a ten-class global land use/land cover (LULC) map for 2020 at $10 \mathrm{~m}$ resolution. The map is derived from ESA Sentinel-2 imagery at $10 \mathrm{~m}$ resolution. This map was produced by a deep learning model trained using over 5 billion hand-labeled Sentinel-2 pixels, sampled from over 20,000 sites distributed across all major biomes of the world (Esri 2021). Since snow/ice is not common in this region, only nine land cover types were considered from the ESRI land cover products. Subfigure (b) is for the topography map of the study area, with the locations of specific analysis sites.

\section{Data and methods}

\subsection{Station data}

The National Meteorological Agency of Ethiopia provided monthly mean rain gauge data for 1992-2009. After excluding the stations with large missing values, sixty-eight stations across the country were considered in this study. Seasonal (June-September) and annual mean rainfall data used in the study were derived from the given monthly mean. The well-known Kriging interpolation method has been applied to estimate the monthly, seasonal, and annual rainfall for the locations lacking gauge observations.

\subsection{Satellite products}

The TAMSAT, v3.1, and CHIRPS v2.0 are the two satellitebased products selected for this study. Both products have the best resolution and cover the study region for an extended period.

TAMSAT satellite is produced at the University of Reading to provide accurate rainfall estimates with high resolution for Continent Africa (Maidment et al. 2014b; Maidment et al. 2017; Tarnavsky et al. 2014). The TAMSAT algorithm works on the assumption that cold cloud-top temperatures (obtained from Meteosat thermal-infrared images) of tropical storms identify raining clouds. The previous versions of this product have been validated in some regions of Africa (Dinku et al. 2007; Herman et al. 1997; Jobard et al. 2011; Laurent et al. 1998; Maidment et al. 2013; Thorne et al. 2001; Tucker et al. 2001). Therefore, the most recent version (TAMSAT v3.1) is used in this study.

CHIRPS is the combination of stations with various satellite products and developed in the University of California by the U.S. Geological Survey and the Climate Hazards Group and available at daily, pentadal, dekadal, and monthly time scales from 1981 to near present (Funk et al. 2015a, 2015b, 2014). CHIRPS is one of the few latest satellite products, in which validation works have been conducted in parts of East Africa and recommended as more reliable to the region than other products (Ayehu et al. 2018; Dinku et al. 
2018; Nkunzimana et al. 2020a). In this study, the monthly average $\left(0.25^{\circ}\right)$ is used for validation.

\subsection{ERA5}

ERA5 is called the fifth-generation reanalysis data set, which extends the popular ERA products family such as ERA-Interim and ERA-40 produced by the European Center for Medium-Range Weather Forecasts (ECMWF) (Hersbach and Dee 2016; Hoffmann et al. 2019). According to Hersbach and Dee (2016), ERA5 was produced by including different characteristics to the ERA-Interim version and available from 1979 to present. The spatial resolution has improved from $79 \mathrm{~km}$ horizontal resolution to $31 \mathrm{~km}$, whereas the temporal resolution from six hours in ERA-Interim to hourly in ERA5 (Hersbach and Dee 2016). The previous versions were validated and reported in East Africa, Uganda (Maidment et al. 2013). The monthly averaged $\left(0.25^{\circ}\right)$ for $1992-2009$ is used for further validation in this study.

\subsection{Data preparation}

The point-scale gauge observations with few missing values were considered for testing the satellite-based and reanalysis products. Since the gauge observation is not representative of the area average, it would be better if the average of some more gauge stations in a pixel were considered for comparison. However, due to the scarcity of gauge stations and also the best resolution of both satellite-based as well as reanalysis data sets, the nearest neighbor-interpolated gridded data from the satellite/model grids to the location of a weather station (grids around the station) were compared with a single-point gauge station. The six regions selected for validation in this study (Fig. 1b) are far apart, have much elevation difference (Table 1), and experience different climate conditions. Considering the complex topography of Ethiopia and variety of land cover types, the selected regions could help understand the performance of these products in different climatic zones. For the average over the country, the Kriging interpolation from sixty-eight-gauge stations was compared with the satellite-based and reanalysis products (Fig. 3).

\subsection{Statistics}

Various skill metrics have been applied to validate the satellite-based and reanalysis products against the independent gauge measurement. Some of the common skill metrics used in this study include Index of Agreement (IA), simple linear regression (slope and coefficient of determination), Pearson's correlation confidence ( $r$ ), Root Mean Square Error (RMSE), Nash and Sutcliffe efficiency (NSE), and BIAS. A detailed description of these and related skill metrics for statistical performance evaluation are presented elsewhere (Dubache et al. 2019a, 2019b;
Fig. 2 Mean monthly climatology of Gauge, TAMSAT 3.1, CHIRPS, and ERA5 rainfall estimates over the selected study sites in Ethiopia (19922009)

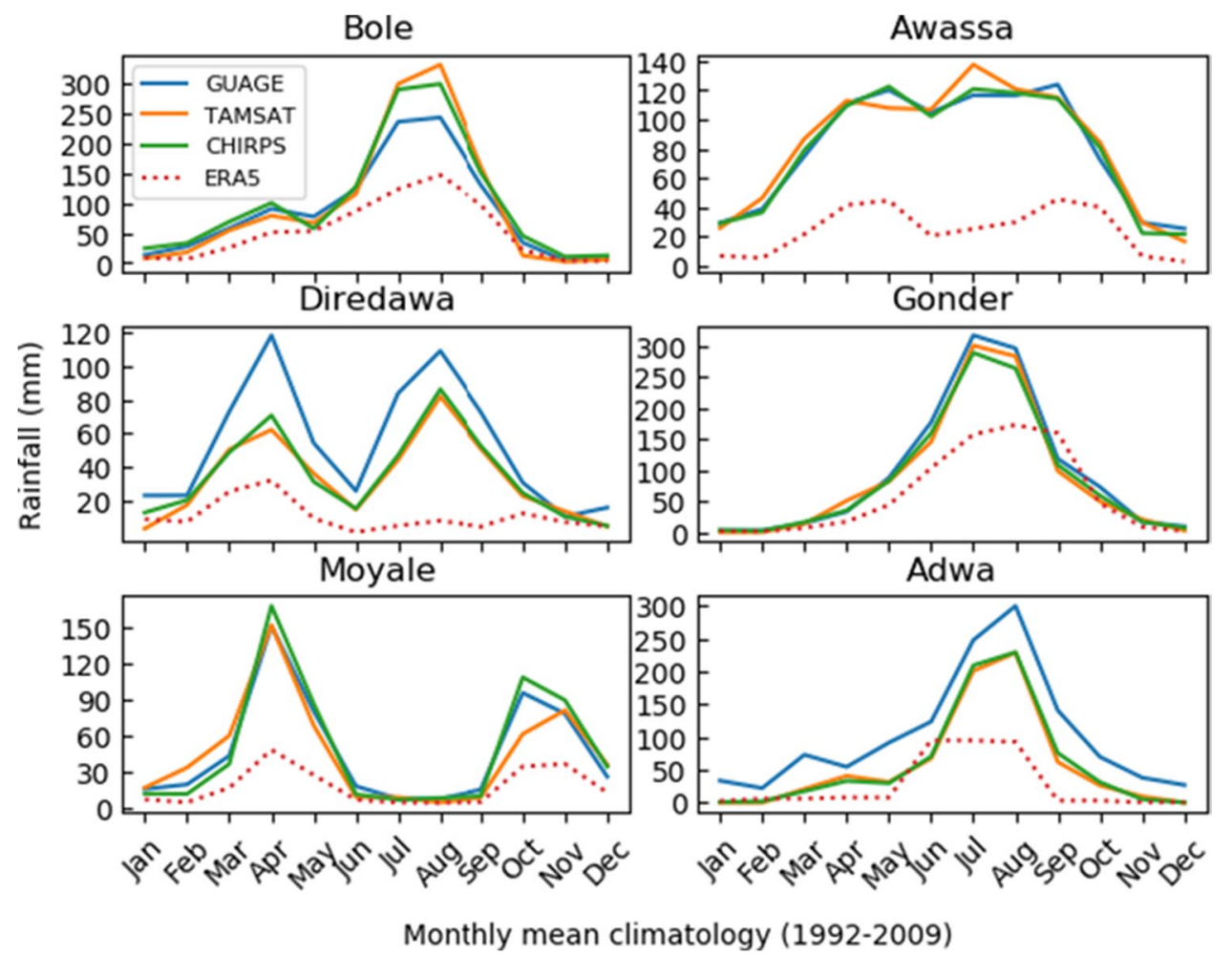

Monthly mean climatology (1992-2009) 
Moriasi et al. 2007; Nageswararao et al. 2018; Nash et al. 1970; Singh et al. 2021). The mathematical expression of the skill metrics used in this study is presented in (Eqs. 1, $2,3,4,5)$.

$$
\begin{aligned}
& I A=1-\frac{\sum_{i=1}^{n}\left(S_{i}-G_{i}\right)^{2}}{\sum_{i=1}^{n}\left(\left|S_{i}-\bar{G}\right|+\left|G_{i}-\bar{G}\right|\right)^{2}} \\
& N S E=1-\frac{\sum_{i=1}^{n}\left(G_{i}-S_{i}\right)^{2}}{\sum_{i=1}^{n}\left(G_{i}-\bar{G}\right)^{2}} \\
& R M S E=\sqrt{\frac{\sum_{i=1}^{n}\left(S_{i}-G_{i}\right)^{2}}{n}} \\
& r=\frac{\sum G_{i} S_{i}-n \overline{G S}}{\sqrt{\left(\sum G_{i}^{2}-n \bar{S}^{2}\right)} \sqrt{\left(\sum G_{i}^{2}-n \bar{S}^{2}\right)}}
\end{aligned}
$$

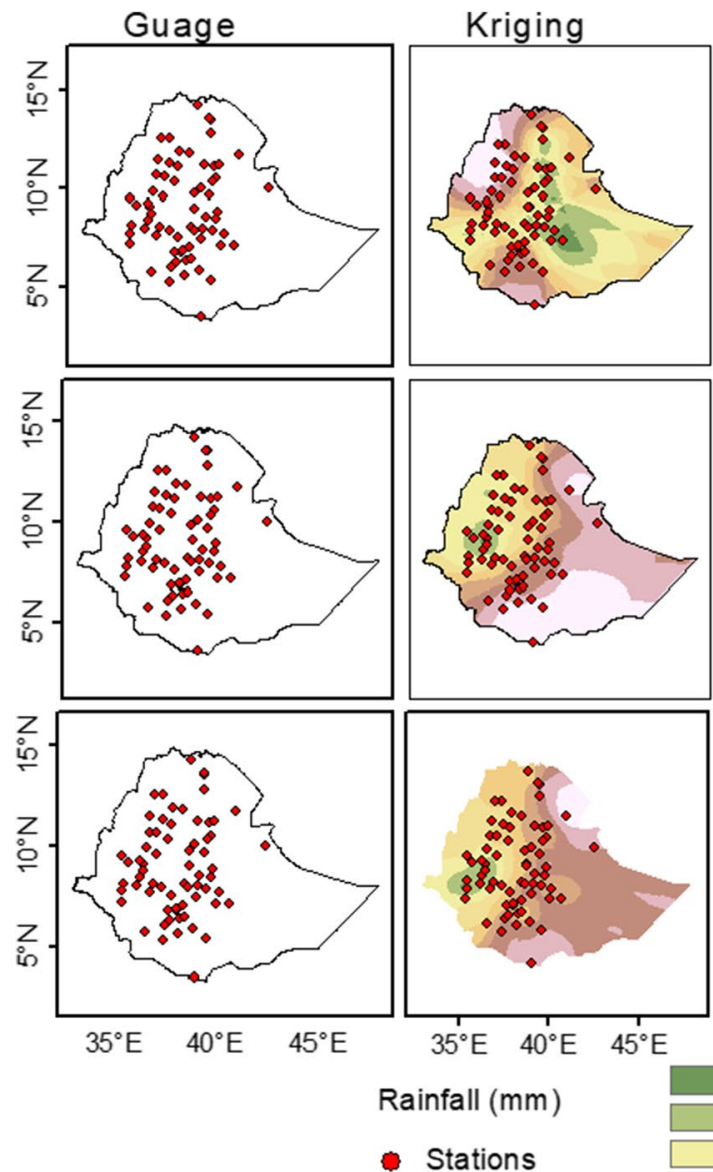

$B I A S=\frac{\sum_{i=1}^{n}\left(S_{i}\right)}{\sum_{i=1}^{n}\left(G_{i}\right)}$

where $\mathrm{i}$ and $\mathrm{n}$, for $\mathrm{i}=1,2, \ldots, \mathrm{n}$ indicate the ith number of gauge, satellite, or model products, whereas $\mathrm{S}, \bar{S}, \mathrm{G}$, and $\bar{G}$ stand for satellite or model products, mean of satellite or model products, and gauge observations, respectively. RMSE is used to measure the absolute mean difference between the satellite- or model-based products and the corresponding gauge observation. RMSE value close to 0 indicates better satellite or model performance. Pearson's correlation confidence $(r)$ is used to measure the linear correlation between satellite- or model-based products and rain gauge data, with -1 and 1 indicating a high negative/positive correlation between the satellite/or model products and gauge observations, respectively. The BIAS is used to measure how much the satellite and model products underestimate or overestimate compared to the gauge observations. The BIAS values close to 1 indicate the best performance of the satellite or model products, whereas less than/or greater than 1 suggests under/overestimation, respectively. The IA index falls between 0 and 1 , with a value closer to 1 indicating
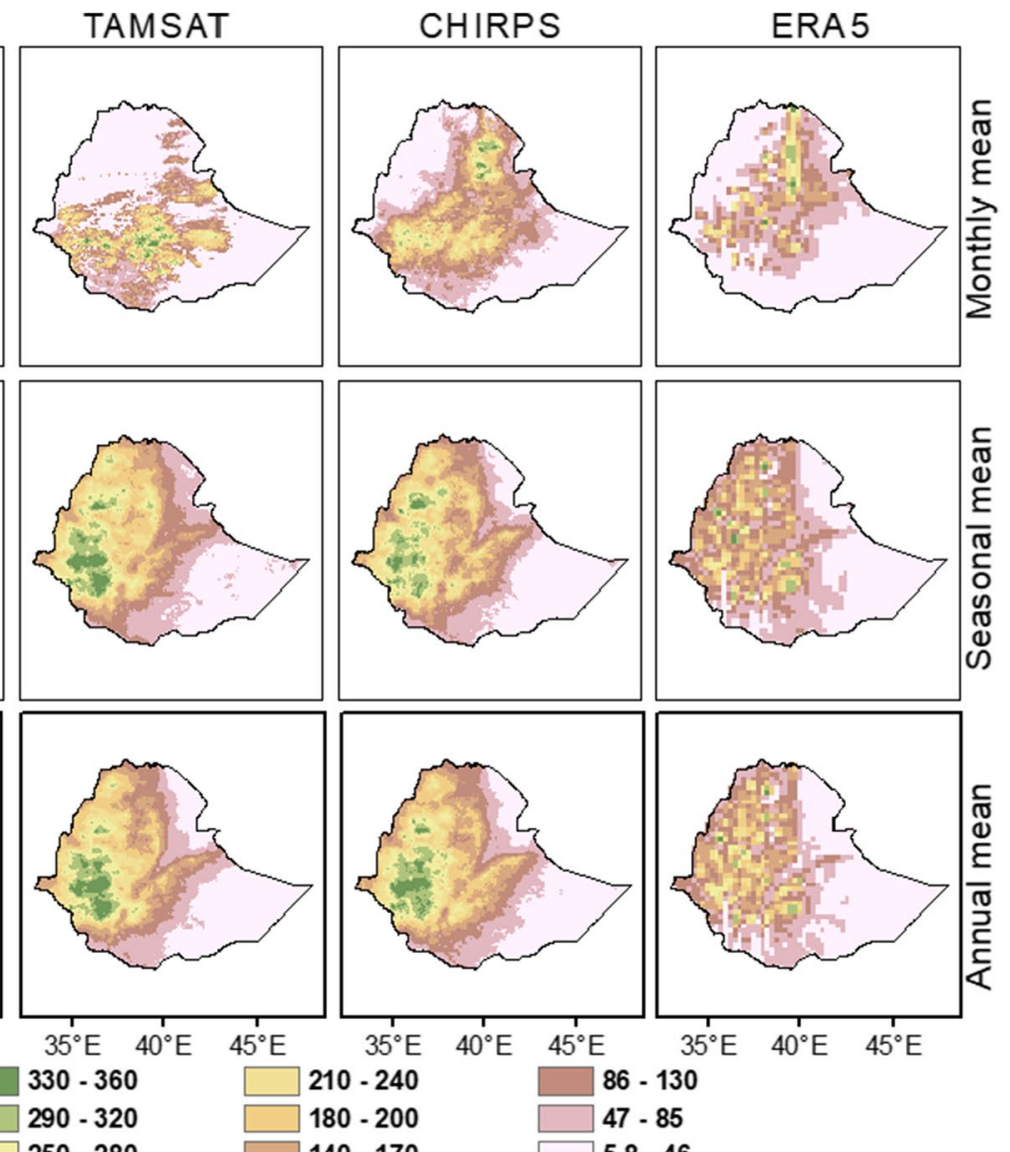

$210-240$
$180-200$
$140-170$

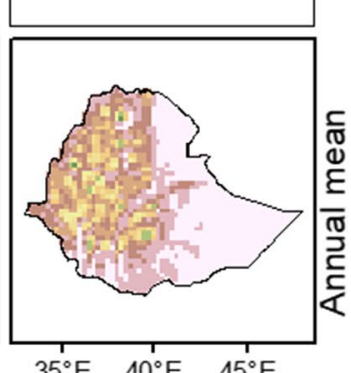

Fig. 3 Gauge, Kinging (interpolation from existing 68-gauge observation stations), TAMSAT 3.1, CHIRPS, and ERA5 monthly mean, seasonal mean, and annual mean rainfall products over Ethiopia (1992-2009) 
Fig. 4 Monthly mean rainfall pattern of Gauge, TAMSAT 3.1, CHIRPS, and ERA5 over the selected study sites in Ethiopia (1992-2009)

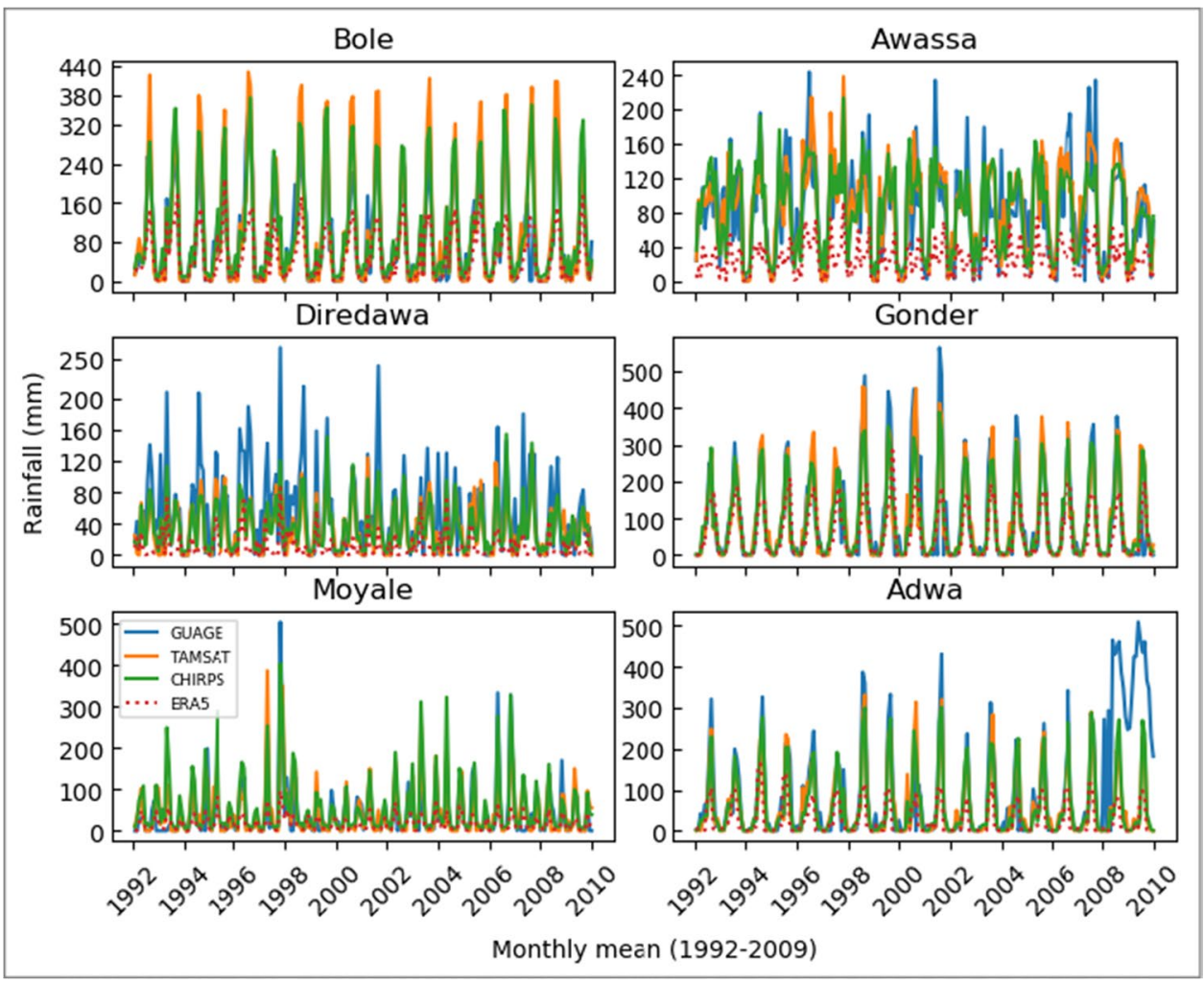

Fig. 5 Linear regression between the monthly mean Gauge and TAMSAT, CHIRPS, ERA5 rainfall estimates in selected study sites in Ethiopia (1992-2009). The subplots (a), (b), (c), (d), (e), and (f) represent the selected study sites Bole, Awassa, Diredawa, Gonder, Moyale, and Adwa, respectively. The grey diagonal line stands for the 1:1 fitting line

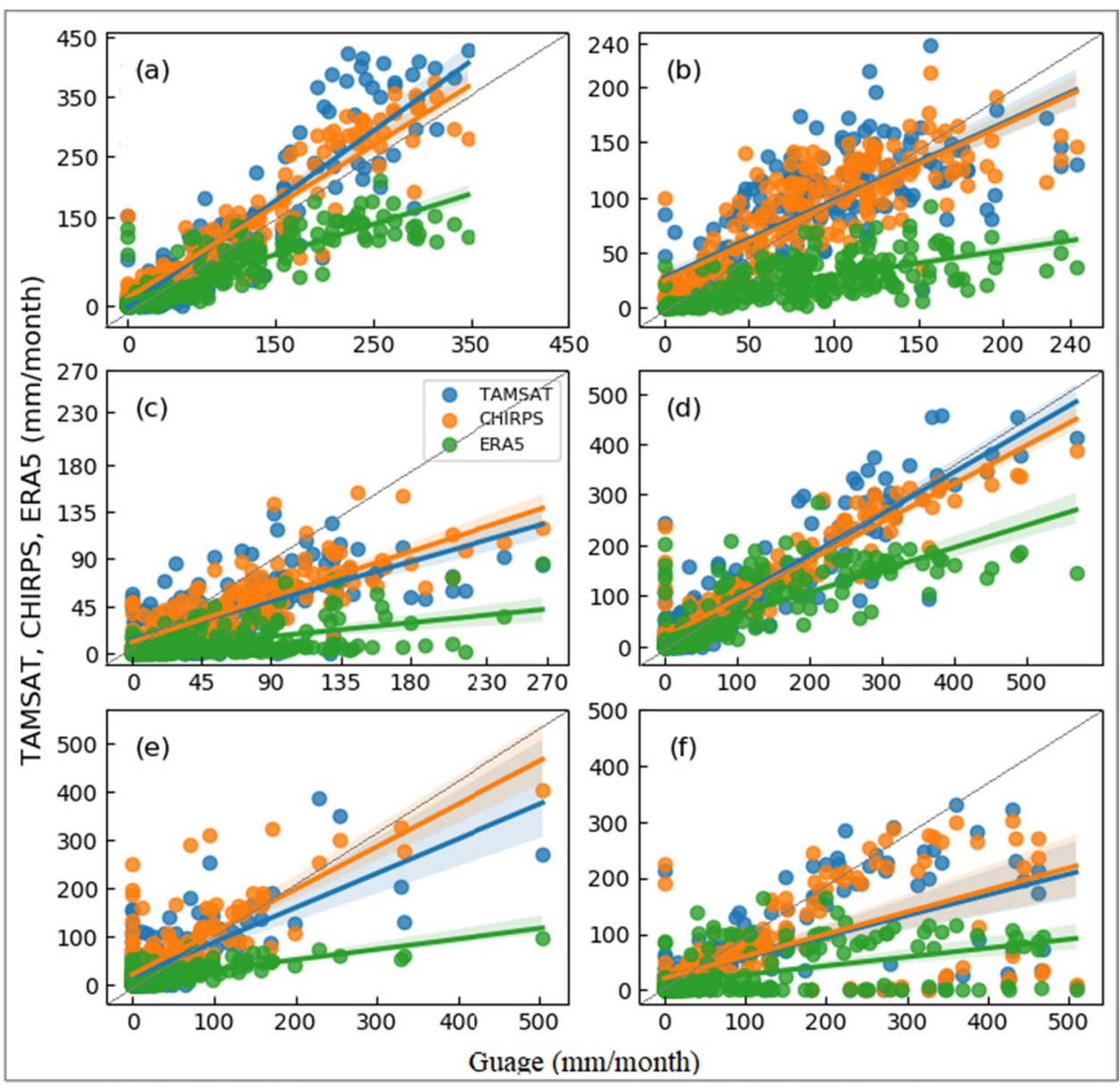


better simulation and otherwise worse. Finally, the NSE is defined to compare the overall deviation of simulations from observations with the observation variance, with 1 telling the best simulation, those values between 0 and 1 showing acceptable model performance, and otherwise worse.

\section{Results}

\subsection{Climatology}

All the products well captured the temporal pattern of the ground observation; however, the reanalysis ERA5 product showed considerable underestimation in all cases, especially during rainy months (Fig. 2). Sites located in the rift valley belt (Dire Dawa and Moyale) followed a bimodal rainfall distribution, while the rest showed a uni-modal regime. March-April and July are rainy months in Dire Dawa, whereas, Moyale receives high rainfall in April, October, and November. The other four sites experience high rainfall June-September. Awassa is also one of the sites located in the rift valley belt but shares a uni-modal regime. The rain in Awassa starts around April and ends around October, which showed a unique pattern compared to other sites. The satellite-based products showed slight overestimation during the rainy season at Bole, Gonder, and Adwa sites but underestimated at the Dire Dawa site. The ERA5 reanalysis product showed underestimation at all locations throughout the study period. The previous product, ERA-40, was validated in Uganda and underestimated the dekadal rainfall estimates (Maidment et al. 2013).

The mean monthly rainfall from sixty-eight-gauge observations with fewer missing values was considered, and the popular kriging interpolation method (Oliver and Webster 1990) was applied to estimate rainfall for the places with no observations (Fig. 3). Kriging was applied to the seasonal and annual mean time cycles derived from mean monthly values. The spatial distribution in (Fig. 3) showed all the products correctly displayed the magnitudes of the rainfall in the region, despite the bias during interpolation due to lack of observations in the southeastern part of the country.
Table 2 Performance indices result for the mean monthly rainfall estimates between gauge and TAMSAT, CHIRPS, and ERA5 products

\begin{tabular}{|c|c|c|c|c|c|c|c|}
\hline & \multicolumn{5}{|l|}{ Monthly } & \multirow[b]{2}{*}{ NSE } & \multirow[b]{2}{*}{ IA } \\
\hline & $r$ & $R^{2}$ & Slope & RMSE & BIAS & & \\
\hline \multicolumn{8}{|l|}{ Bole } \\
\hline TAMSAT & $0.87 * * *$ & $0.76^{* *}$ & 1.18 & 0.62 & 1.16 & 0.52 & 0.91 \\
\hline CHIRPS & $0.90 * * *$ & $0.81 * *$ & 1.02 & 0.47 & 1.18 & 0.73 & 0.94 \\
\hline ERA5 & $0.87 * * *$ & $0.75 * *$ & 0.51 & 0.60 & 0.62 & 0.55 & 0.82 \\
\hline TAMSAT & $0.76^{* *}$ & $0.58^{* *}$ & 0.70 & 0.37 & 1.04 & 0.55 & 0.87 \\
\hline \multicolumn{8}{|l|}{ Awassa } \\
\hline CHIRPS & $0.81 * *$ & $0.66^{* *}$ & 0.70 & 0.32 & 1.01 & 0.66 & 0.90 \\
\hline ERA5 & $0.66 * *$ & $0.43 *$ & 0.23 & 0.72 & 0.30 & -0.68 & 0.56 \\
\hline TAMSAT & $0.71 * *$ & $0.51 *$ & 0.41 & 0.43 & 0.65 & 0.37 & 0.74 \\
\hline \multicolumn{8}{|l|}{ Dire } \\
\hline CHIRPS & $0.83 * *$ & $0.68 * *$ & 0.48 & 0.37 & 0.68 & 0.52 & 0.81 \\
\hline ERA5 & $0.52 *$ & $0.27 *$ & 0.15 & 0.64 & 0.20 & -0.42 & 0.52 \\
\hline TAMSAT & $0.90 * * *$ & $0.80 * *$ & 0.83 & 0.55 & 0.97 & 0.80 & 0.94 \\
\hline \multicolumn{8}{|l|}{ Gonder } \\
\hline CHIRPS & $0.93 * * *$ & $0.86 * * *$ & 0.76 & 0.48 & 0.94 & 0.85 & 0.95 \\
\hline ERA5 & $0.79 * *$ & $0.62 * *$ & 0.44 & 0.88 & 0.63 & 0.49 & 0.78 \\
\hline TAMSAT & $0.73 * *$ & $0.54 *$ & 0.71 & 0.46 & 1.17 & 0.47 & 0.85 \\
\hline \multicolumn{8}{|l|}{ Moyale } \\
\hline CHIRPS & $0.79 * *$ & $0.62 * *$ & 0.88 & 0.47 & 1.45 & 0.44 & 0.87 \\
\hline ERA5 & $0.73 * *$ & $0.54 *$ & 0.22 & 0.55 & 0.45 & 0.24 & 0.55 \\
\hline TAMSAT & $0.61 * *$ & $0.37 *$ & 0.37 & 1.10 & 0.60 & 0.28 & 0.72 \\
\hline \multicolumn{8}{|l|}{ Adwa } \\
\hline CHIRPS & $0.64 * *$ & $0.41 *$ & 0.39 & 1.07 & 0.61 & 0.32 & 0.74 \\
\hline ERA5 & $0.50 *$ & $0.25^{*}$ & 0.16 & 1.34 & 0.28 & -0.07 & 0.51 \\
\hline
\end{tabular}

The symbols $r, R^{2}$, RMSE, IA, and NSE stands for Pearson's correlation coefficient, coefficient of determination, Root Mean Square Error, index of agreement, and Nash and Sutcliffe efficiency, respectively

The asterisks $(*, * *, * * *)$ stand for significance levels of $p<0.05,0.01$, and 0.001 , respectively 
This region usually experiences quite a low rainfall and has no significant influence on the country's economy. Compared to the reanalysis ERA output product, both satellitebased products better reflected the rainfall distributions at seasonal and annual scales.

\subsection{Monthly mean rainfall}

The mean monthly rainfall distribution pattern was well captured by both the satellite-based products and the reanalysis product, despite the different magnitudes of bias in each case (Fig. 4). The ERA5 product showed considerable underestimation at all selected study sites, while the satellite products were underestimated significantly at the Dire Dawa site, which is located in the Eastern part of the country and experiences a bi-model rainfall distribution, and overestimated at the Bole site.

The qualitative regression results (Fig. 5) and the performance indices (Table 2) explain the relationship between the compared constituents. ERA5 has shown a considerable underestimation with a relatively low correlation compared to the satellite products. Both (Fig. 6c and f) showed significant depreciation by both satellite products; however, the large bias in (Fig. 5f) is due to the outlier of gauge observation toward the last two years of the study period (see, Fig. 4, Adwa).

The scatter plot in (Fig. 5) presented the various magnitude of underestimated values of both satellites and reanalysis almost in all cases, except Bole, which has slight overestimation in satellite products. Despite the difference in accuracy from site to site, CHIRPS showed better results in most cases, except the Gonder site (Fig. 5d), in which TAMSAT outperformed. Both satellite products showed a large bias in Adwa (Fig. 5f) and moderate bias in Dire Dawa (Fig. 5c). ERA5 was found to be highly biased/underestimated for all products at all sites.

According to the skill metrics results (Table 2), various magnitudes of performance were observed at the monthly time scale. In this case, except for two sites (Moyale and Adwa), CHIRPS showed high performance in all other locations with high correlation coefficient, coefficient of determination, index of agreement, and low RMSE and BIAS values. For the CHIRPS, in most cases, the NSE values are above 0.5 and the slopes are above 0.6 and below 1.2. TAMSAT followed CHIRPS with the slightest difference in most cases, whereas ERA5 showed less performance than the satellite products, yet still significant in most cases.

\subsection{Seasonal mean rainfall}

June-September is the main rainy season in Ethiopia. Except for Moyale other five study sites in (Fig. 6) are influenced by this season. Compared to the monthly mean, the seasonal mean rainfall pattern was less captured by all products. The
Fig. 6 Seasonal mean (JuneSeptember) rainfall pattern of gauge, TAMSAT 3.1, CHIRPS, and ERA5 over the selected study in Ethiopia (1992-2009)

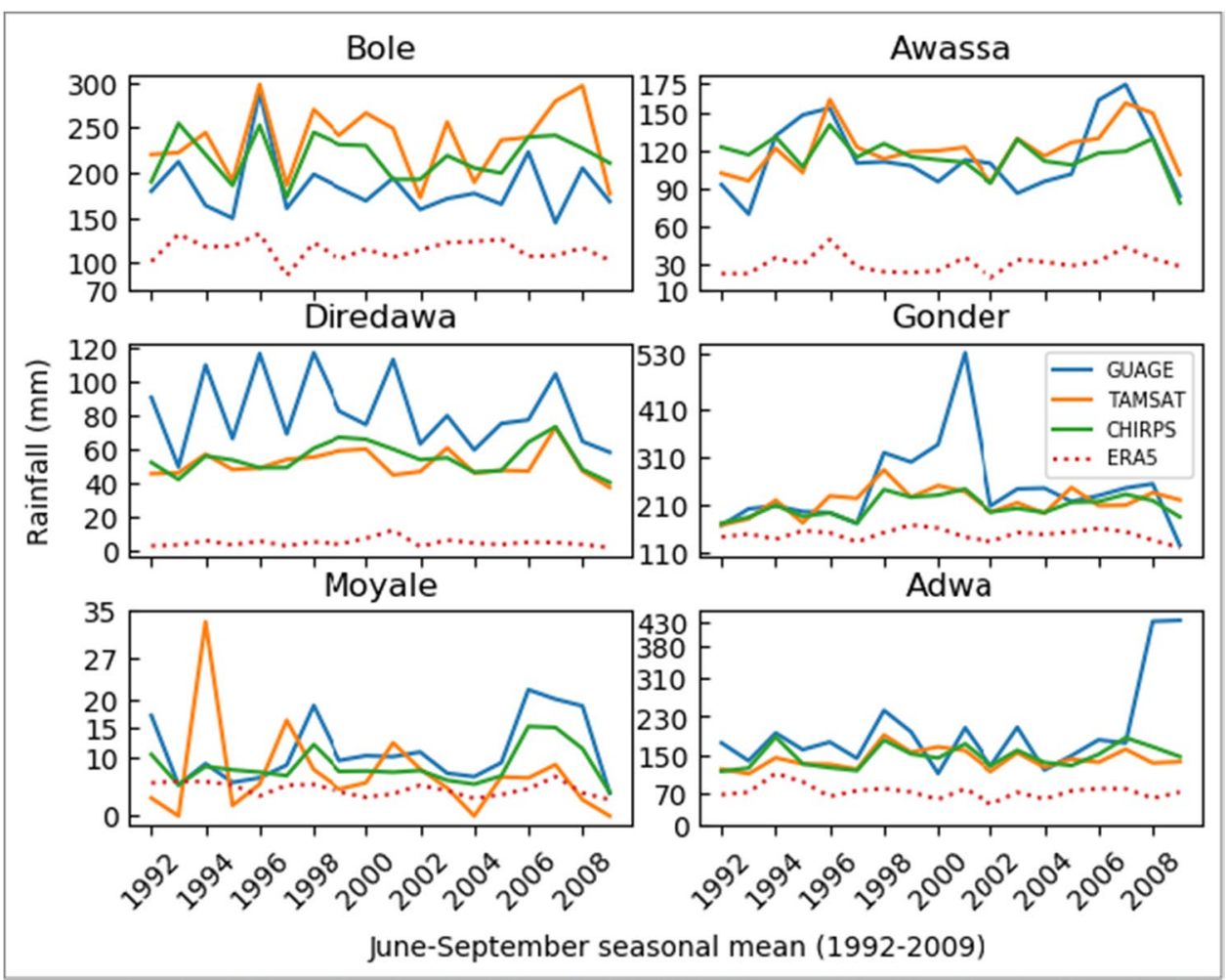


quantitative analysis results in Table 3 and the regression plot (Fig. 7) testified the same. Thus, the negative bias of ERA5 in all study sites and the nearly close magnitude of both satellitebased products reflect what is presented in the monthly case.

Despite the struggle to capture the seasonal pattern of the rainfall adequately, CHIRPS still performed well in finding the phase of gauge observations (Fig. 6). The regression plot in (Fig. 7) and performance indices values in Table 3 indicated that CHIRPS has slightly better performance than TAMSAT, except the Awassa site in which TAMSAT outperformed. The ERA5 product is underestimated in all cases but still significant.

In the case of the seasonal time scale, the products were less accurate compared to monthly performance. However, still, CHIRPS performed well with the seasonal average correlation coefficient of 0.59, Root Mean Square Error of 0.47 , and BIAS value of 0.89 . In contrast, TAMSAT is next with the correlation coefficient of 0.36, Root Mean Square Error of 0.53, and BIAS value of 0.76. ERA5 showed a better correlation in two individual cases; however, the overall average is less with the correlation coefficient 0.40, RMSE
0.89 , and BIAS value 0.38 . Finally, the quantitative results at the Moyale site (which is not rainy during this season) in Table 3 indicated that CHIRPS matched very well with the gauge observation during normal conditions.

The scatter plot (Fig. 7) can be seen with the corresponding metrics results in Table 3 to confirm the sizeable negative bias of ERA5 in all study sites (Fig. 7a-f) and the corresponding plot without ERA5 (Fig. 7g-1). The plot presented the over/underestimation by the products and the struggle to capture the pattern of the seasonal rainfall distribution at each study site.

\subsection{Annual mean rainfall}

The performance of the products at an annual scale falls somewhere between monthly and seasonal time scales. For example, in (Fig. 8) all the products tried to capture the shape of yearly mean rainfall distribution and the corresponding statistics results in Table 4 showed moderately good performance.
Table 3 Performance indices result for the mean seasonal rainfall estimates between gauge and TAMSAT, CHIRPS, and ERA5 products

\begin{tabular}{|c|c|c|c|c|c|c|c|}
\hline & \multicolumn{5}{|l|}{ Seasonal } & \multirow[b]{2}{*}{ NSE } & \multirow[b]{2}{*}{ IA } \\
\hline & $r$ & $R^{2}$ & Slope & RMSE & BIAS & & \\
\hline \multicolumn{8}{|l|}{ Bole } \\
\hline TAMSAT & $0.49^{*}$ & $0.24 *$ & 0.57 & 0.63 & 1.28 & -2.62 & 0.53 \\
\hline CHIRPS & $0.57 * *$ & $0.33^{*}$ & 0.41 & 0.43 & 1.18 & -0.70 & 0.62 \\
\hline ERA5 & $0.40^{*}$ & $0.16^{*}$ & 0.14 & 0.76 & 0.62 & -4.29 & 0.38 \\
\hline TAMSAT & $0.63^{* *}$ & $0.40^{*}$ & 0.43 & 0.22 & 1.05 & 0.35 & 0.76 \\
\hline \multicolumn{8}{|l|}{ Awassa } \\
\hline CHIRPS & $0.34^{*}$ & $0.12 *$ & 0.17 & 0.27 & 1.01 & 0.09 & 0.51 \\
\hline ERA5 & $0.65^{* *}$ & $0.43^{*}$ & 0.18 & 0.89 & 0.26 & $-9-09$ & 0.34 \\
\hline TAMSAT & $0.40 *$ & $0.16^{*}$ & 0.15 & 0.36 & 0.63 & -1.91 & 0.49 \\
\hline \multicolumn{8}{|l|}{ Dire } \\
\hline CHIRPS & $0.51 *$ & $0.26^{*}$ & 0.21 & 0.33 & 0.67 & -1.39 & 0.53 \\
\hline ERA5 & $0.59 * *$ & $0.34^{*}$ & 0.06 & 0.79 & 0.06 & -13.15 & 0.31 \\
\hline TAMSAT & $0.47 *$ & $0.22 *$ & 0.15 & 0.82 & 0.89 & 0.11 & 0.44 \\
\hline \multicolumn{8}{|l|}{ Gonder } \\
\hline CHIRPS & $0.78 * *$ & $0.61 * *$ & 0.20 & 0.80 & 0.85 & 0.15 & 0.51 \\
\hline ERA5 & $0.32 *$ & 0.10 & 0.04 & 1.28 & 0.61 & -1.18 & 0.43 \\
\hline TAMSAT & 0.06 & 0.00 & 0.09 & 0.10 & 0.71 & -2.29 & 0.42 \\
\hline \multicolumn{8}{|l|}{ Moyale } \\
\hline CHIRPS & $0.94 * * *$ & $0.89 * * *$ & 0.54 & 0.04 & 0.74 & 0.53 & 0.82 \\
\hline ERA5 & $0.39 *$ & $0.15^{*}$ & 0.08 & 0.08 & 0.36 & -1.32 & 0.48 \\
\hline TAMSAT & $0.13^{*}$ & 0.02 & 0.03 & 1.06 & 0.87 & -0.42 & 0.41 \\
\hline \multicolumn{8}{|l|}{ Adwa } \\
\hline CHIRPS & $0.37^{*}$ & $0.14 *$ & 0.10 & 0.98 & 0.87 & -0.21 & 0.45 \\
\hline ERA5 & 0.03 & 0.00 & 0.00 & 1.55 & 0.39 & -2.01 & 0.40 \\
\hline
\end{tabular}

The symbols $r, R^{2}$, RMSE, IA, and NSE stands for Pearson's correlation coefficient, coefficient of determination, Root Mean Square Error, index of agreement, and Nash and Sutcliffe efficiency, respectively

The asterisks $(*, * *, * * *)$ stand for significance levels of $p<0.05,0.01$, and 0.001 , respectively. The $r$ and $R^{2}$ values without asterisks indicate insignificance (i.e., $p>0.05$ ) 
Annual mean rainfall pattern of gauge, TAMSAT 3.1, CHIRPS, and ERA5 over the selected study sites in Ethiopia (1992-2009).

The performance of the products at an annual scale falls somewhere between monthly and seasonal time scales. For example, in (Fig. 8) all the products tried to capture the shape of yearly mean rainfall distribution and the corresponding statistics results in Table 4 showed moderately good performance.
The reanalysis product is still underestimated but relatively better compared to the seasonal scale. The regression subplots (Fig. 9g-f) were used to see the results excluding the ERA5 product, which is mainly biased at all sites throughout the study time range.

All the products have relatively better performance (Table 4) with slight differences from site to site. CHIRPS achieved better with the average correlation coefficient of 0.63, Root Mean Square Error of 0.17, and BIAS value of

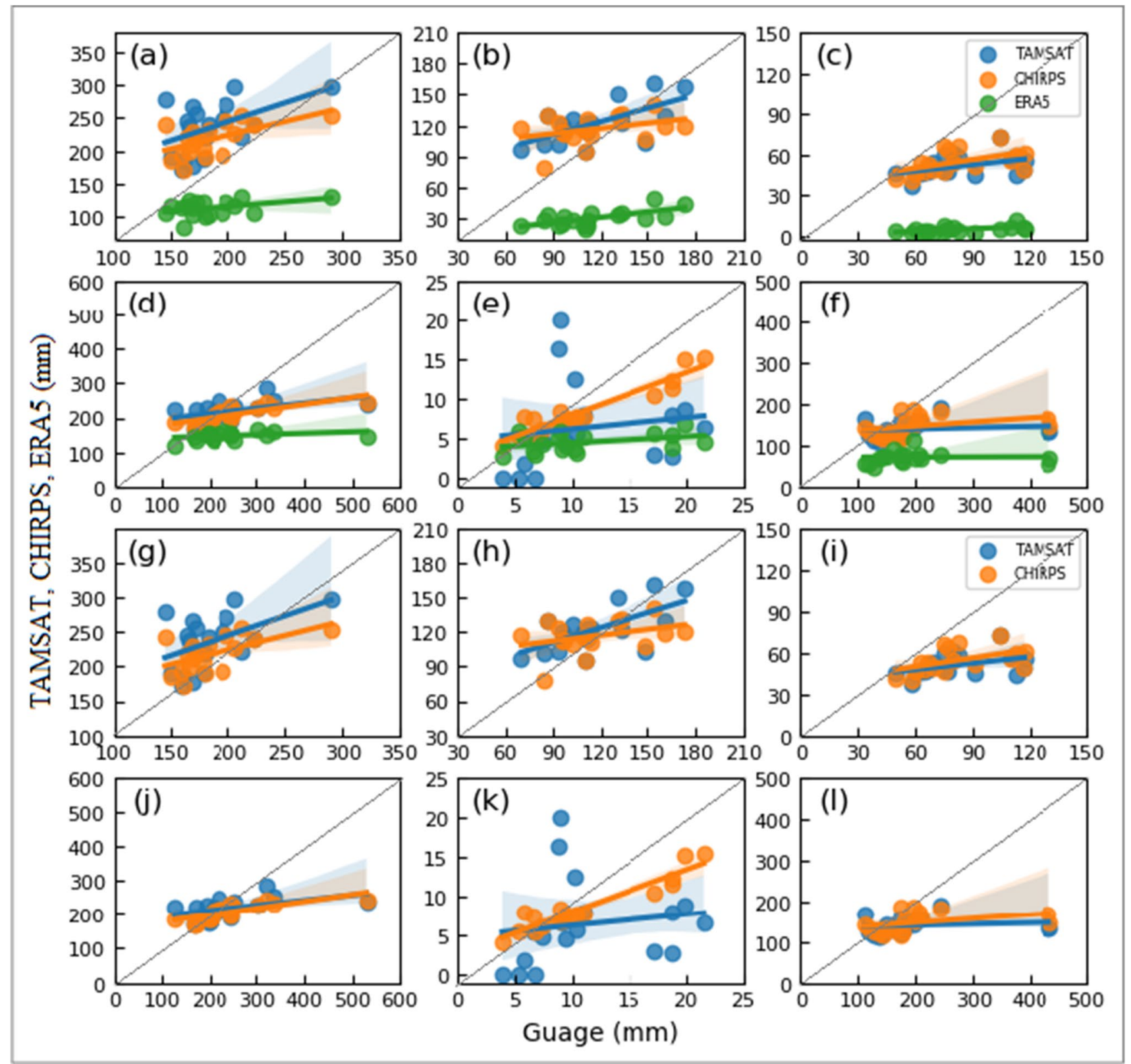

Fig. 7 Linear regression between seasonal mean (June-September) gauge and TAMSAT, CHIRPS, ERA5 rainfall estimates in selected study sites in Ethiopia (1992-2009). The subplots (a), (b), (c), (d), (e), and (f) represent the selected study sites Bole, Awassa, Diredawa,
Gonder, Moyale, and Adwa, respectively. The corresponding (g), (h), (i), (j), (k), and (l) stand for the same sites but excluding the ERA5 data set. The grey diagonal line stands for the 1:1 fitting line 
0.97. TAMSAT also performed well with the average correlation coefficient of 0.60; Root Mean Square Error of 0.17 and BIAS value of 0.95 . In the case of ERA5, 0.65, 0.44, and 0.42 are the average correlation coefficient, Root Mean Square Error, and BIAS values, respectively. The index of agreement is above average in most cases, but NSE values are good only in few cases. For the detailed statistical results of individual study sites, see Tables 2, 3, and 4 for monthly, seasonal, and annual time scales, respectively.

The monthly, seasonal, and annual mean and total, as well as their difference of gauge, TAMSAT, CHIRPS, and ERA5 data sets of all sites are presented in Table 5. From this, it is obvious to see the magnitude of the bias based on the difference between gauge and other products. As clearly indicated in the above results, the bias correction results also reflected the large difference between gauge and ERA5 data in all sites. TAMSAT and CHIRPS also showed noticeable differences with the gauge in some cases, low compared to ERA5.

4.5 .

\section{Discussion}

The observed monthly mean rainfall data were used to validate TAMSAT, CHIRPS, and ERA5 precipitation products. Despite the considerable underestimation of the ERA5 product, all three products were able to capture the climatological pattern of the rainfall in sites. The spatial pattern over the country also showed that the products could indicate the rainfall amounts in different regions. Statistically, the satellite products are much better than the reanalysis products, which showed significant underestimation in all study sites and cycles. The results showed that all the products outperformed on a monthly scale compared to seasonal and annual scales. CHIRPS showed slightly better accuracy than TAMSAT at monthly scale. This agrees with a recent study in the region (Dinku et al. 2018), which reported that CHIRPS performed slightly better than TAMSAT (version 3) at dekadal and monthly scales. CHIRPS still performed better in capturing the shapes and estimating the magnitudes of the seasonal rainfall amounts. The same is true on the annual scale, even though TAMSAT showed slightly better performance in few cases. Another study in East African country, Burundi (Nkunzimana et al. 2020a), has also reported the execution of CHIRPS at the annual time scale compared to other satellite products. The poor performance of the satellites in capturing the pattern and estimating the magnitudes of the seasonal rainfalls can be attributed to various factors. For instance, the complex topography of the study region, the nature of heavy seasonal rain in the region, and the possible limitation in algorithm design could be some of the reasons. Derin and Yilmaz (2014) evaluated several satellite products globally. They reported that all the satellite-based estimations have
Fig. 8 Annual mean rainfall pattern of gauge, TAMSAT 3.1, CHIRPS, and ERA5 over the selected study sites in Ethiopia (1992-2009)

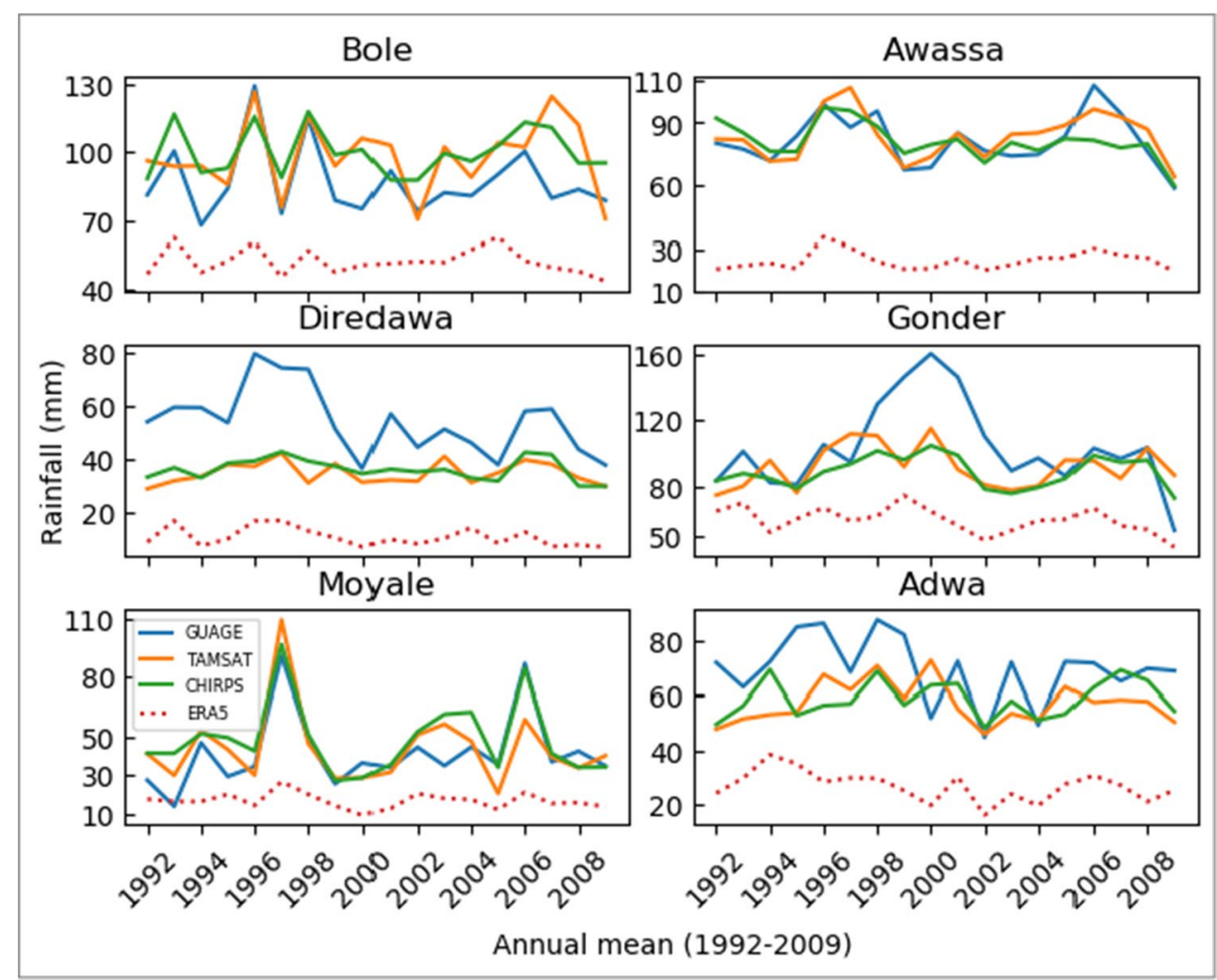


difficulties representing the precipitation gradient normal to the elevated terrain. The evaluation work on several satellite products worldwide showed a general underestimation of heavy precipitation over eastern Africa (Sun et al. 2018; Thiemig et al. 2012).

Both CHIRPS and TAMSAT are highly accepted and widely used products in the region. But, to be honest, TAMSAT is supposed to be better than CHIRPS, especially in this study region, for some reasons. Firstly, it has a much higher spatial resolution $\left(0.0375^{\circ}\right)$ than CHIRPS $\left(0.25^{\circ}\right.$, monthly) and other data sources that cover this study region. Secondly, the CHIRPS satellite uses a fixed rain/no rain temperature threshold, whereas TAMSAT uses a varying condition (Dinku et al. 2018), so both products have nearly similar algorithms. Thirdly, TAMSAT has a single goal of having accurate rainfall estimates in Africa considering more detailed continental conditions, while CHIRPS satellite covers beyond. Last but not least, TAMSAT estimates have been validated over the complex terrain of Ethiopia (which is also the region of this study) and demonstrated good skills
(Maidment et al. 2017). Yet, still, CHIRPS performs better in all cases, except at a daily scale (Dinku et al. 2018).

Most satellite products include rain gauge measurements from the Global Telecommunications System, which only considers synoptic observations. Despite a limited number of synoptic observations in the Global Telecommunications System, it also reports sporadically (Dinku et al. 2014). It was reported that about 20-gauge stations are accessible from Ethiopia through the Global Telecommunications System, while a country has over 500 gauges (Dinku et al. 2014). So, CHIRPS might have access to the more significant number of gauges in the region during the calibration, whereas TAMSAT did not. Another study in the region pointed out the difficulty of local calibration due to accessing the rain gauge data (Dinku et al. 2011) and suggested the products could be improved through blending with gauge observations. These might be some of the reasons behind the less accuracy of the satellite products.

The reanalysis model output product (ERA5) showed large negative bias almost in all cases and was less accurate
Table 4 Performance indices result for the mean annual rainfall estimates between gauge and TAMSAT, CHIRPS, and ERA5 products

\begin{tabular}{|c|c|c|c|c|c|c|c|}
\hline & \multicolumn{5}{|l|}{ Annual } & \multirow[b]{2}{*}{ NSE } & \multirow[b]{2}{*}{ IA } \\
\hline & $r$ & $R^{2}$ & Slope & RMSE & BIAS & & \\
\hline \multicolumn{8}{|l|}{ Bole } \\
\hline TAMSAT & $0.58 *$ & $0.34 *$ & 0.61 & 0.18 & 1.13 & -0.42 & 0.70 \\
\hline CHIRPS & $0.74 * *$ & $0.55^{*}$ & 0.51 & 0.16 & 1.15 & -0.18 & 0.70 \\
\hline ERA5 & $0.67 * *$ & $0.45^{*}$ & 0.24 & 0.37 & 0.60 & -4.88 & 0.40 \\
\hline TAMSAT & $0.77 * *$ & $0.59 *$ & 0.71 & 0.08 & 1.03 & 0.54 & 0.87 \\
\hline \multicolumn{8}{|l|}{ Awassa } \\
\hline CHIRPS & $0.61 *$ & $0.37 *$ & 0.44 & 0.10 & 0.99 & 0.36 & 0.75 \\
\hline ERA5 & $0.74 * *$ & $0.55^{*}$ & 0.26 & 0.58 & 0.30 & -21.98 & 0.26 \\
\hline TAMSAT & $0.38 *$ & $0.15^{*}$ & 0.13 & 0.23 & 0.64 & -2.45 & 0.45 \\
\hline \multicolumn{8}{|l|}{ Dire } \\
\hline CHIRPS & $0.72 * *$ & $0.51 *$ & 0.23 & 0.21 & 0.67 & -1.86 & 0.49 \\
\hline ERA5 & $0.70 * *$ & $0.49 *$ & 0.20 & 0.45 & 0.20 & -12.51 & 0.31 \\
\hline TAMSAT & $0.46^{*}$ & $0.21 *$ & 0.22 & 0.26 & 0.89 & -0.01 & 0.57 \\
\hline \multicolumn{8}{|l|}{ Gonder } \\
\hline CHIRPS & $0.77 * *$ & $0.59 *$ & 0.28 & 0.25 & 0.86 & 0.09 & 0.60 \\
\hline ERA5 & $0.48 *$ & $0.23 *$ & 0.14 & 0.50 & 0.58 & -2.73 & 0.43 \\
\hline TAMSAT & $0.79 * *$ & $0.63 *$ & 0.81 & 0.12 & 1.06 & 0.56 & 0.88 \\
\hline \multicolumn{8}{|l|}{ Moyale } \\
\hline CHIRPS & $0.84 * * *$ & $0.71 * *$ & 0.82 & 0.12 & 1.16 & 0.57 & 0.89 \\
\hline ERA5 & $0.65^{* *}$ & $0.42 *$ & 0.14 & 0.30 & 0.41 & -1.53 & 0.43 \\
\hline TAMSAT & 0.1 & 0.01 & -0.01 & 1.05 & 0.95 & -0.26 & 0.33 \\
\hline \multicolumn{8}{|l|}{ Adwa } \\
\hline CHIRPS & 0.09 & 0.01 & 0.01 & 1.03 & 0.97 & -0.21 & 0.33 \\
\hline ERA5 & 0.14 & 0.02 & -0.01 & 1.21 & 0.42 & -0.68 & 0.38 \\
\hline
\end{tabular}

The symbols $r, R^{2}$, RMSE, IA, and NSE stands for Pearson's correlation coefficient, coefficient of determination, Root Mean Square Error, index of agreement, and Nash and Sutcliffe efficiency, respectively

The asterisks $(*, * *, * * *)$ stand for significance levels of $p<0.05,0.01$, and 0.001 , respectively. The $r$ and $R^{2}$ values without asterisks indicate insignificance (i.e., $p>0.05$ ) 


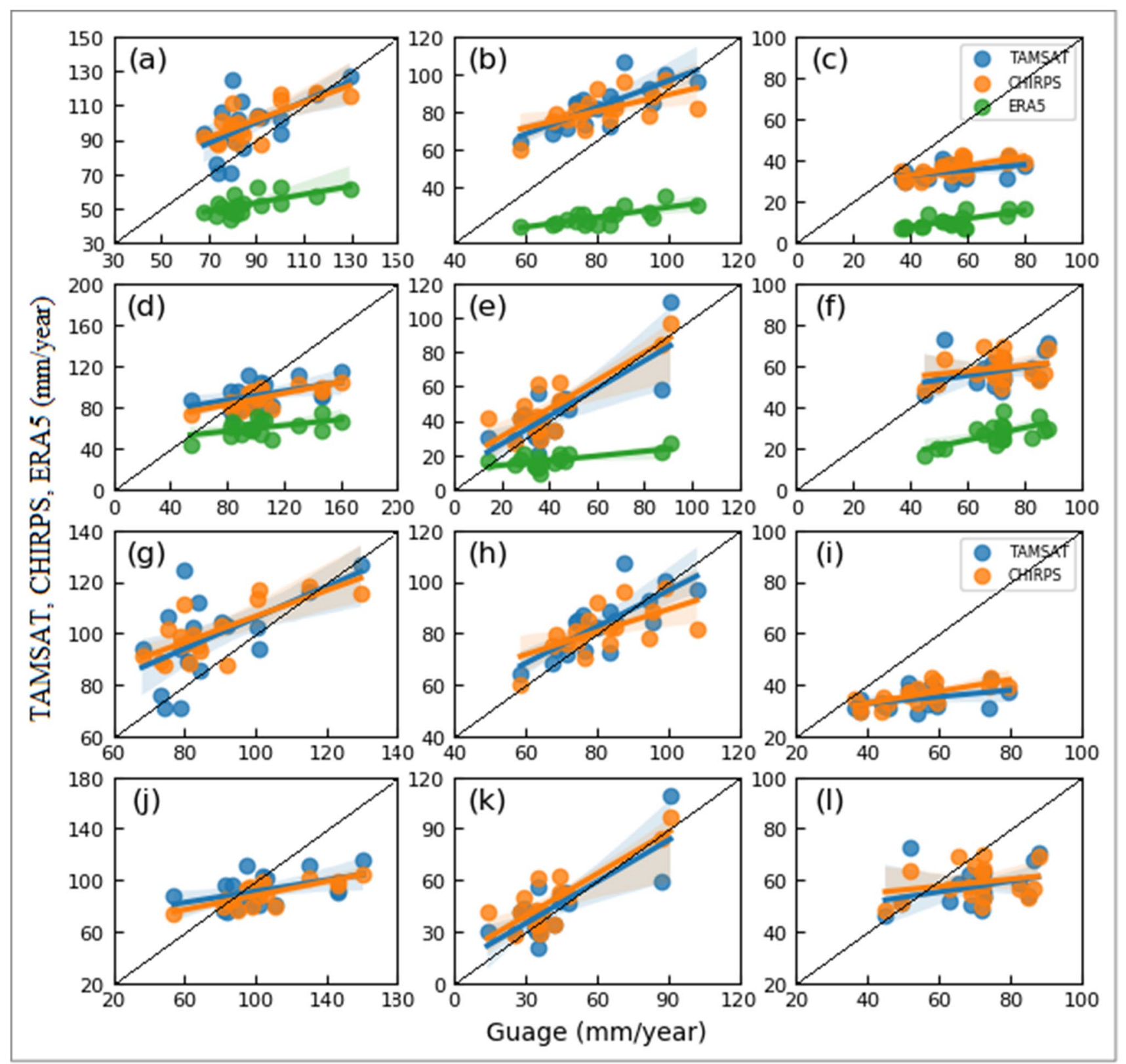

Fig. 9 Linear regression between the annual mean gauge and TAMSAT, CHIRPS, ERA5 rainfall estimates in selected study sites in Ethiopia (1992-2009). The subplots (a), (b), (c), (d), (e), and (f) represent the selected study sites Bole, Awassa, Diredawa, Gonder, Moy- ale, and Adwa, respectively. The corresponding (g), (h), (i), (j), (k), and (l) stand for the same sites but excluding the ERA5 data set. The grey diagonal line stands for the 1:1 fitting line

precipitation (Maidment et al. 2014a), and the uncertainties in these approximations could lead to bulky errors in the estimated rainfall (Allan et al. 2007; Flato et al. 2014; Pearson et al. 2014; Pope et al. 2000; Yang and Slingo 2001). The latest ERA5 product, which operated at around $30 \mathrm{~km}$ grid resolution, still resulted in a large underestimation in all the cases considered in this study. The previous version of this product (ERA-40) was validated in Uganda at dekadal time scale (Maidment et al. 2013) but still underestimated. scale processes associated with tropical convection and 
Table 5 The difference in total and average values of the gauge against satellite/model products

\begin{tabular}{|c|c|c|c|c|c|c|c|c|c|c|c|c|c|}
\hline \multirow[t]{2}{*}{ Sites } & \multirow{2}{*}{ Data type } & \multicolumn{4}{|c|}{ Monthly } & \multicolumn{4}{|c|}{ Seasonal } & \multicolumn{4}{|c|}{ Annual } \\
\hline & & Total & Total-df & Average & Ave-df & Total & Total-df & Average & Ave-df & Total & Total-df & Average & Ave-df \\
\hline \multirow[t]{4}{*}{ Bole } & Guage & 18,256 & & 85 & & 3309 & & 184 & & 1568 & & 87 & \\
\hline & TAMSAT & 21,227 & 2971 & 98 & 14 & 4236 & 926 & 235 & 51 & 1769 & 201 & 98 & 11 \\
\hline & CHIRPS & 21,620 & 3364 & 100 & 16 & 3909 & 600 & 217 & 33 & 1802 & 233 & 100 & 13 \\
\hline & ERA & 11,338 & -6918 & 52 & -32 & 2048 & -1261 & 114 & -70 & 945 & -623 & 52 & -35 \\
\hline \multirow[t]{4}{*}{ Awassa } & Guage & 17,357 & & 80 & & 2083 & & 116 & & 1463 & & 81 & \\
\hline & TAMSAT & 17,995 & 638 & 83 & 3 & 2196 & 113 & 122 & 6 & 1500 & 36 & 83 & 2 \\
\hline & CHIRPS & 17,497 & 140 & 81 & 1 & 2096 & 13 & 116 & 1 & 1458 & -5 & 81 & 0 \\
\hline & ERA & 5262 & $-12,095$ & 24 & -56 & 548 & -1536 & 30 & -85 & 438 & -1025 & 24 & -57 \\
\hline \multirow[t]{4}{*}{ Dire } & Guage & 11,491 & & 53 & & 1466 & & 81 & & 976 & & 54 & \\
\hline & TAMSAT & 7466 & -4026 & 35 & -19 & 921 & -545 & 51 & -30 & 622 & -354 & 35 & -20 \\
\hline & CHIRPS & 7789 & -3702 & 36 & -17 & 981 & -486 & 54 & -27 & 649 & -327 & 36 & -18 \\
\hline & ERA & 2272 & -9219 & 11 & -43 & 85 & -1382 & 5 & -77 & 189 & -787 & 11 & -44 \\
\hline \multirow[t]{4}{*}{ Gonder } & Guage & 20,511 & & 95 & & 4408 & & 245 & & 1873 & & 104 & \\
\hline & TAMSAT & 19,886 & -625 & 92 & -3 & 3931 & -477 & 218 & -27 & 1657 & -216 & 92 & -12 \\
\hline & CHIRPS & 19,236 & -1275 & 89 & -6 & 3735 & -673 & 208 & -37 & 1603 & -270 & 89 & -15 \\
\hline & ERA & 12,950 & -7561 & 60 & -35 & 2668 & -1740 & 148 & -97 & 1079 & -794 & 60 & -44 \\
\hline \multirow[t]{4}{*}{ Moyale } & Guage & 8110 & & 38 & & 199 & & 11 & & 749 & & 42 & \\
\hline & TAMSAT & 9482 & 1372 & 44 & 6 & 128 & -71 & 7 & -4 & 790 & 41 & 44 & 2 \\
\hline & CHIRPS & 11,749 & 3639 & 54 & 17 & 154 & -46 & 9 & -3 & 870 & 122 & 48 & 7 \\
\hline & ERA & 3656 & -4454 & 17 & -21 & 82 & -117 & 5 & -7 & 305 & -444 & 17 & -25 \\
\hline \multirow[t]{4}{*}{ Adwa } & Guage & 20,778 & & 96 & & 3562 & & 198 & & 1850 & & 103 & \\
\hline & TAMSAT & 12,403 & -8375 & 57 & -39 & 2516 & -1046 & 140 & -58 & 1034 & -817 & 57 & -45 \\
\hline & CHIRPS & 12,718 & -8059 & 59 & -37 & 2634 & -929 & 146 & -52 & 1060 & -790 & 59 & -44 \\
\hline & ERA & 5807 & $-14,971$ & 27 & -69 & 1288 & -2274 & 72 & -126 & 484 & -1366 & 27 & -76 \\
\hline
\end{tabular}

Total and average stand for the total sum and average rainfall of gauge, TAMSAT, CHIRPS, and ERA5 of all sites at monthly, seasonal, and annual scales, respectively, whereas total-df and ave-df stand for the difference of total sum and average values between the gauge and other indirect estimates of all sites at monthly, seasonal, and annual time scales, respectively

\section{Conclusion}

Historical records indicate that Ethiopia lost millions of lives due to the devastating drought and most of those droughts were directly associated with the failure of seasonal rainfall. The satellite-based and numerical model output rainfall estimates are the best alternatives to replace the region's sparse and discontinuous ground-based observations. Thus, the frequent drought and flood events could better be forecasted and monitored. According to some previous studies, CHIRPS is a reliable product among several freely available satellite-based rainfall estimates in the region. In this study, two recently produced high-resolution satellite-based products such as CHIRPS and TAMSAT and one latest released high-resolution reanalysis model output product (ERA5) were evaluated using gauge observations. The evaluation was conducted at monthly, seasonal, and annual time scales at six different sites in Ethiopia. The results indicated that the CHIRPS product performed well in all cases and TAMSAT followed with the slightest difference.
On the other hand, the reanalysis model output product showed considerable underestimation in all cases. Thus, despite the negligible differences, both satellite-based products can be reliable in the region. Still, it would be better to compare both products against the in situ observations before application for the site-based research works. Furthermore, the algorithms need further calibration with quality and enough gauge observations to improve the estimation of seasonal rainfall amounts.

Acknowledgements The authors are thankful to the University of Reading for the financial support and National Meteorology Agency of Ethiopia for providing the meteorological data. Thanks to Dr. Loza B. for the technical support.

Author contributions All authors contributed, read, and commented on previous versions of the manuscript and approved the final manuscript.

Funding This work was supported by the University of Reading.

Data availability The satellite-based and numerical model output data sets are freely available from their websites; however, the gauge data are not available due to the agreement with the source organization. 


\section{Declarations}

Conflict of interest The authors declare that there is no financial or personal conflict of interest.

Ethical approval Not applicable, because this article does not contain any studies with human or animal subjects.

Consent to participate Consent to participate was not required for this study.

Consent for publication Consent for publication was not required for this study.

Open Access This article is licensed under a Creative Commons Attribution 4.0 International License, which permits use, sharing, adaptation, distribution and reproduction in any medium or format, as long as you give appropriate credit to the original author(s) and the source, provide a link to the Creative Commons licence, and indicate if changes were made. The images or other third party material in this article are included in the article's Creative Commons licence, unless indicated otherwise in a credit line to the material. If material is not included in the article's Creative Commons licence and your intended use is not permitted by statutory regulation or exceeds the permitted use, you will need to obtain permission directly from the copyright holder. To view a copy of this licence, visit http://creativecommons.org/licenses/by/4.0/.

\section{References}

Allan RP, Slingo A, Milton SF, Brooks ME (2007) Evaluation of the met office global forecast model using geostationary earth radiation budget (GERB) data. Q J R Meteorol Soc 133:1993-2010

Ayehu GT, Tadesse T, Gessesse B, Dinku T (2018) Validation of new satellite rainfall products over the Upper Blue Nile Basin, Ethiopia. Atmos. Meas. Tech. https://doi.org/10.5194/ amt-11-1921-2018

Bai L, Shi C, Li L, Yang Y, Wu J (2018) Accuracy of CHIRPS satelliterainfall products over mainland China. Remote Sens 10:362

Becker A, Finger P, Meyer-Christoffer A, Rudolf B, Schamm K, Schneider U, Ziese M (2013) A description of the global landsurface precipitation data products of the global precipitation climatology centre with sample applications including centennial (trend) analysis from 1901-present. Earth Syst Sci Data 5:71

Bergès JC, Jobard I, Chopin F, Roca R, EPSAT-SG (2010) A satellite method for precipitation estimation; its concepts and implementation for the AMMA experiment. AnGeo, Copernicus GmbH 289-308.

Derin Y, Yilmaz KK (2014) Evaluation of multiple satellite-based precipitation products over complex topography. J Hydrometeorol 15:1498-1516

Dinku T, Ceccato P, Grover-Kopec E, Lemma M, Connor S, Ropelewski C (2007) Validation of satellite rainfall products over East Africa's complex topography. Int J Remote Sens 28:1503-1526

Dinku T, Chidzambwa S, Ceccato P, Connor S, Ropelewski C (2008a) Validation of high-resolution satellite rainfall products over complex terrain. Int J Remote Sens 29:4097-4110

Dinku T, Connor SJ, Ceccato P, Ropelewski CF (2008b) Comparison of global gridded precipitation products over a mountainous region of Africa. Int J Climatol 28:1627-1638
Dinku T, Ceccato P, Connor SJ (2011) Challenges of satellite rainfall estimation over mountainous and arid parts of east Africa. Int J Remote Sens 32:5965-5979

Dinku T, Hailemariam K, Maidment R, Tarnavsky E, Connor S (2014) Combined use of satellite estimates and rain gauge observations to generate high-quality historical rainfall time series over Ethiopia. Int J Climatol 34:2489-2504

Dinku T, Funk C, Peterson P, Maidment R, Tadesse T, Gadain H, Ceccato $\mathrm{P}$ (2018) Validation of the CHIRPS satellite rainfall estimates over eastern Africa. Q J R Meteorol Soc 144:292-312

Diro G, Grimes D, Black E, O’Neill A, Pardo-Iguzquiza E (2009) Evaluation of reanalysis rainfall estimates over Ethiopia. Int J Climatol 29:67-78

Dubache G, Li S, Zheng X, Zhang W, Deng J (2019a) Modeling ammonia volatilization following urea application to winter cereal fields in the United Kingdom by a revised biogeochemical model. Sci Total Environ 660:1403-1418

Dubache G, Ogwang BA, Ongoma V, Islam ARMT (2019b) The effect of Indian Ocean on Ethiopian seasonal rainfall. Meteorol Atmos Phys 131:1753-1761

Esri (2021) Esri 2020 Land Cover. https://www.arcgis.com/home/item. html?id=d6642f8a4f6d4685a24ae2dc0c73d4ac

Flato G, Marotzke J, Abiodun B, Braconnot P, Chou SC, Collins W, Cox P, Driouech F, Emori S, Eyring V (2014) Evaluation of climate models. Climate change 2013: the physical science basis. Contribution of Working Group I to the Fifth Assessment Report of the Intergovernmental Panel on Climate Change. Cambridge University Press, Cambridge, pp 741-866

Funk CC, Peterson PJ, Landsfeld MF, Pedreros DH, Verdin JP, Rowland JD, Romero BE, Husak GJ, Michaelsen JC, Verdin AP (2014) A quasi-global precipitation time series for drought monitoring. USGS 832:1-12

Funk C, Peterson P, Landsfeld M, Pedreros D, Verdin J, Shukla S, Husak G, Rowland J, Harrison L, Hoell A (2015a) The climate hazards infrared precipitation with stations - a new environmental record for monitoring extremes. Sci Data 2:1-21

Funk C, Verdin A, Michaelsen J, Peterson P, Pedreros D, Husak G (2015b) A global satellite assisted precipitation climatology. Earth Syst 8

Harris I, Jones PD, Osborn TJ, Lister DH (2014) Updated high-resolution grids of monthly climatic observations-the CRU TS3. 10 Dataset. Int J Climatol 34:623-642

Herman A, Kumar VB, Arkin PA, Kousky JV (1997) Objectively determined 10-day African rainfall estimates created for famine early warning systems. Int J Remote Sens 18:2147-2159

Hersbach H, Dee D (2016) ERA5 reanalysis is in production, ECMWF Newsletter 147. Reading, UK: ECMWF. https://www.ecmwf.int/ en/newsletter/147/news/era5-reanalysis-production

Hoffmann L, Günther G, Li D, Stein O, Wu X, Griessbach S, Heng Y, Konopka P, Müller R, Vogel B (2019) From ERA-Interim to ERA5: the considerable impact of ECMWF's next-generation reanalysis on Lagrangian transport simulations. Atmos Chem Phys 19(5):3097-3124

Huffman GJ, Adler RF, Bolvin DT, Nelkin EJ (2010) The TRMM multi-satellite precipitation analysis (TMPA). Satellite rainfall applications for surface hydrology. Springer, Dordrecht, pp 3-22

Jobard I, Chopin F, Bergès JC, Roca R (2011) An intercomparison of 10-day satellite precipitation products during West African monsoon. Int J Remote Sens 32:2353-2376

Koutsouris AJ, Chen D, Lyon SW (2016) Comparing global precipitation data sets in eastern Africa: a case study of Kilombero Valley, Tanzania. Int J Climatol 36:2000-2014

Laurent H, Jobard I, Toma A (1998) Validation of satellite and ground-based estimates of precipitation over the Sahel. AtmRe 47:651-670 
Lim HS, Ho CH (2000) Comparison of tropical rainfall between the observed GPCP data and the assimilation products of ECMWF, NCEP/NCAR, and NASA-GEOS-1. J Metrol Soc Jpn Ser II 78:661-672

Maidment R, Grimes DI, Allan RP, Greatrex H, Rojas O, Leo O (2013) Evaluation of satellite-based and model reanalysis rainfall estimates for Uganda. MeApp 20:308-317

Maidment RI, Grimes D, Allan RP, Tarnavsky E, Stringer M, Hewison T, Roebeling R, Black E (2014) The 30 year TAMSAT African rainfall climatology and time series (TARCAT) data set. J Geophys Res-Atmos 119:644

Maidment RI, Grimes D, Black E, Tarnavsky E, Young M, Greatrex H, Allan RP, Stein T, Nkonde E, Senkunda S (2017) A new, longterm daily satellite-based rainfall dataset for operational monitoring in Africa. Sci Data 4:63

Menne MJ, Durre I, Vose RS, Gleason BE, Houston TG (2012) An overview of the global historical climatology network-daily database. J Atmos Ocean Technol 29:897-910

Moriasi DN, Arnold JG, Van Liew MW, Bingner RL, Harmel RD, Veith TL (2007) Model evaluation guidelines for systematic quantification of accuracy in watershed simulations. Trans ASABE 50:885-900

Nageswararao M, Mohanty U, Ramakrishna S, Dimri A (2018) An intercomparison of observational precipitation data sets over Northwest India during winter. Theoret Appl Climatol 132:181-207

Nash JE, Sutcliffe JV (1970) River flow forecasting through conceptual models part I-A discussion of principles. J Hydrol 10:282-290

Nkunzimana A, Bi S, Alriah MAA, Zhi T, Kur NAD (2020) Comparative analysis of the performance of satellite-based rainfall products over various topographical unities in Central East Africa: case of Burundi. Earth Space Sci 7:834

Novella NS, Thiaw WM (2013) African rainfall climatology version 2 for famine early warning systems. J Appl Meteorol Climatol 52:588-606

Oliver MA, Webster R (1990) Kriging: a method of interpolation for geographicalinformation systems. Int J Geogr Inf Syst 4(3):313-332

Pearson K, Lister G, Birch C, Allan R, Hogan R, Woolnough S (2014) Modelling the diurnal cycle of tropical convection across the 'grey zone.' Q J R Meteorol Soc 140:491-499

Poccard I, Janicot S, Camberlin P (2000) Comparison of rainfall structures between NCEP/NCAR reanalyses and observed data over tropical Africa. Clim Dyn 16:897-915

Pope V, Gallani M, Rowntree P, Stratton R (2000) The impact of new physical parametrizations in the Hadley Centre climate model: HadAM3. Clim Dyn 16:123-146
Roebeling R, Wolters E, Meirink J, Leijnse H (2012) Triple collocation of summer precipitation retrievals from SEVIRI over Europe with gridded rain gauge and weather radar data. J Hydrometeorol 13:1552-1566

Romilly TG, Gebremichael M (2011) Evaluation of satellite rainfall estimates over Ethiopian river basins. Hydrol Earth Syst Sci 15:1505

Schneider U, Becker A, Finger P, Meyer-Christoffer A, Ziese M, Rudolf B (2014) GPCC's new land surface precipitation climatology based on quality-controlled in situ data and its role in quantifying the global water cycle. Theor Appl Climatol 115:15-40

Schreck CJ III, Semazzi FH (2004) Variability of the recent climate of eastern Africa. Int J Climatol 24:681-701

Singh T, Saha U, Prasad V, Gupta MD (2021) Assessment of newlydeveloped high resolution reanalyses (IMDAA, NGFS and ERA5) against rainfall observations for Indian region. Atmos Res 259:105679

Sun Q, Miao C, Duan Q, Ashouri H, Sorooshian S, Hsu KL (2018) A review of global precipitation data sets: data sources, estimation, and intercomparisons. Rev Geophys 56:79-107

Tarnavsky E, Grimes D, Maidment R, Black E, Allan RP, Stringer M, Chadwick R, Kayitakire F (2014) Extension of the TAMSAT satellite-based rainfall monitoring over Africa and from 1983 to present. J Appl Meteorol Climatol 53:2805-2822

Thiemig V, Rojas R, Zambrano-Bigiarini M, Levizzani V, De Roo A (2012) Validation of satellite-based precipitation products over sparsely gauged African river basins. J Hydrometeorol 13:1760-1783

Thorne V, Coakeley P, Grimes D, Dugdale G (2001) Comparison of TAMSAT and CPC rainfall estimates with raingauges, for southern Africa. Int J Remote Sens 22:1951-1974

Tucker M, Sear C (2001) A comparison of Meteosat rainfall estimation techniques in Kenya. Meteorol Appl 8:107-117

Ullah W, Wang G, Ali G, Tawia Hagan DF, Bhatti AS, Lou D (2019) Comparing multiple precipitation products against in-situ observations over different climate regions of Pakistan. Remote Sens $11: 628$

Yang GY, Slingo J (2001) The diurnal cycle in the tropics. Mon Weather Rev 129:784-801

Zhang Q, Körnich H, Holmgren K (2013) How well do reanalyses represent the southern African precipitation? Clim Dyn 40:951-962

Publisher's note Springer Nature remains neutral with regard to jurisdictional claims in published maps and institutional affiliations. 